\title{
Langkah “Merah” Pemikiran Pendidikan Tan Malaka, 1919-1921
}

\author{
Satriono Priyo Utomo
}

\author{
Program Studi S2 Ilmu Sejarah, Fakultas Ilmu Budaya, Universitas Indonesia \\ Kampus Universitas Indonesia, Depok, Jawa Barat- Indonesia \\ *Alamat korespondensi: utomo_satrio@rocketmail.com \\ DOI: https://doi.org/10.14710/jscl.v5i2.22023
}

Diterima/Received: 11 Februari 2019; Direvisi/ Revised: 31 Desember 2020; Disetujui/ Accepted: 31 December 2020

\begin{abstract}
The historiography of Tan Malaka, which has been frequently found, discusses his personality as a revolutionary figure, living from one prison to another. The consistency of Tan Malaka in struggling for the absolute independence has been studied for years by the Dutch historian, Harry Poeze. Departing from historiography about Tan Malaka in which have written by Harry Poeze, this study uses the historical method. It discusses Tan Malaka's thoughts on education which originated from his publication in 1921 entitled Sarekat Islam and Onderwijs. Where it can be seen that Tan Malaka puts education as a political tool, in which it has the goal of shaping Indonesian people not only to be intelligent but also to refine their feelings. He rejected the rote learning method that make people become foolish and mechanical-type like machines. Tan Malaka's figure as a political actor has been scrutinized and written comprehensively by using historical source which become adequate. However, there are still very few studies that discuss Tan Malaka's thought. In the activities of practical politics, Tan Malaka was a productive revolutionary figure eflecting his thoughts in a number of works. Not many of the published works have examined Tan Malaka's thoughts about his views on education. Tan Malaka is a movement figure who chose studies in the field of pedagogy (education).
\end{abstract}

Keywords: Tan Malaka; Thoughts; Education; Politics; Sarekat Islam.

\section{Abstrak}

Historiografi tentang Tan Malaka yang sering dijumpai membicarakan sosoknya sebagai kaum pergerakan yang revolusioner, hidup dari penjara ke penjara. Konsistensi Tan Malaka dalam perjuangannya menuntut kemerdekaan penuh dan hal ini telah diteliti bertahun-tahun oleh sejarawan Belanda, yaitu Harry Poeze. Bertolak pada historiografi tentang Tan Malaka yang ditulis Harry Poeze, penelitian ini menggunakan metode sejarah ini, membahas mengenai pemikiran Tan Malaka tentang pendidikan yang bersumber dari tulisannya pada 1921 berjudul Sarekat Islam dan Onderwijs. Dalam tulisan itu, Tan Malaka menempatkan pendidikan sebagai alat politik dengan tujuan membentuk manusia Indonesia yang tidak hanya cerdas secara intelektual, tetapi juga halus perasaannya. Ia dengan tegas menolak metode pembelajaran hafalan yang menjadikan bodoh dan mekanis seperti mesin. Sosok Tan Malaka sebagai aktor politik telah ditulis secara komprehensif dengan sumber sejarah yang sangat memadai, tetapi masih jarang penelitian yang membahas mengenai pemikiran Tan Malaka. Di dalam kesibukan politik praktis yang dilakukan, Tan Malaka adalah tokoh pergerakan yang produktif dan mampu merefleksikan pemikirannya melalui sejumlah karya. Tidak banyak ilmuan yang meneliti mengenai pemikiran Tan Malaka dalam bidang pendidikan, padahal Tan Malaka adalah tokoh pergerakan yang juga mengkaji menganai pedagogi (pendidikan).

Keywords: Tan Malaka; Pemikiran; Pendidikan; Politik; Sarekat Islam.

\section{Pendahuluan}

Nama Tan Malaka kian populer ketika rezim Soeharto jatuh. Tulisan-tulisannya diterbitkan kembali dan menjadi bacaan anak-anak muda yang merindukan sosok pejuang dan pemikir yang revolusioner. Tan Malaka juga menjadi bahan diskusi yang tidak habis-habisnya untuk diteliti.
Sarjana Barat seperti Harry Poeze mendedikasikan hidupnya bertahun-tahun untuk melakukan penelitian terhadap sosok yang disebut Alfian (1978) sebagai pejuang revolusioner yang kesepian. Penelitian Harry Poeze membuka ruang bagi peneliti lain terutama sarjana Indonesia untuk menuliskan dan memberikan tempat yang 
semestinya bagi salah satu founding fathers Indonesia.

Melalui dua sarjana Indonesia, Rambe (2003) dan Fa'al (2010), pemikiran Tan Malaka dalam bidang politik telah diteliti. Jika Rambe menuliskan pemikiran-pemikiran filosofis Tan Malaka berdasar pada karya Madilog (1943), Fa'al menuliskan pokok-pokok pemikiran Tan Malaka tentang negara dan revolusi sosial. Keduanya berangkat atas dasar ketertarikan bahwa sosok Tan Malaka adalah pemikir revolusioner yang memiliki konsepsi terhadap masa depan Indonesia jauh sebelum kaum pergerakan lain memikirkannya. Tidak sedikit tokoh-tokoh pergerakan yang terinspirasi dari pemikiran-pemikiran Tan Malaka. Sukarno adalah pembaca buku-buku karya Tan Malaka seperti Naar de Republiek (1925). Lirik lagu Indonesia Raya yang dibuat oleh W.R. Supratman terinspirasi dari bacaan bukunya atas karya Tan Malaka berjudul Massa Actie (1926) (Tim Tempo, 2010, p. 90).

Pada esensinya, pemikiran dan perjuangan Tan Malaka terpusat kepada tujuan untuk memerdekakan bangsanya, sekaligus merombak secara total dalam bidang politik, ekonomi, sosial, dan budaya (Abdullah, 1978, p. 151). Bagi Tan Malaka, pendidikan dinilai sebagai salah satu alat untuk mencapai kemerdekaan dan melawan penindasan kolonial. Mendidik anak-anak Indonesia merupakan pekerjaan yang paling mulia dan penting pada masa itu. Penguasaan bahasa menjadi salah satu instrumen untuk memajukan pendidikan seluruh kalangan, termasuk bagi masyarakat pribumi (Suwignyo, 2013, pp. 487488). Bahasa Belanda bukan bahasa pengantar, dan kebudayaan Belanda bukanlah arah pendidikan kita (Malaka, 2008, p. 47).Sementara itu, arah, dasar, dan tata cara untuk pelaksanaan pendidikan meskipun dinilai telah jelas, tetapi arah, dasar, dan cara itu masih bertentangan dengan yang dianut oleh penjajah Belanda.

Tan Malaka adalah lulusan sekolah guru dan telah mengajar di dua tempat yaitu Sumatera dan Jawa. Saat berada di Jawa (Semarang), Tan Malaka mencurahkan pemikiran-pemikirannya mengenai pendidikan yang berbeda dari pendidikan yang telah dijalankan oleh sistem kolonial Belanda. Tidak banyak penelitian dari sarjana Barat dan Indonesia yang melihat pemikiran-pemikiran Tan Malaka tentang pendidikan. Hal itu menarik untuk diteliti mengenai bagaimana konsep pemikiranpemikiran pendidikan Tan Malaka yang lebih menitikberatkan kepada konsepsi pendidikan yang revolusioner sebagai antitesa dari pendidikan kolonial yang menindas.

Kajian ini menerapkan metode sejarah yang mencakup empat tahap, yaitu heuristik, kritik sumber, interpretasi fakta, dan historiografi. Fokus kajian ini mendiskusikan tentang pemikiran pendidikan kerakyatan Tan Malaka yang bersumber dari tulisannya berjudul Serikat Islam Semarang dan Onderwijs (1921). Dalam tulisan itu, Tan Malaka memiliki gagasan ideal mengenai dasar dan praktik pendidikan yang harus dilakukan oleh bangsa Indonesia. Ia menilai bahwa orientasi pendidikan harus memiliki prinsip membebaskan kaum tertindas. Selain itu, sumber dari penelitian terdahulu tentang Tan Malaka yang dilakukan oleh Poeze (2000), Fa'al (2010), Ihsanudin (2010), dan sebagainya, juga telah ditinjau dalam kajian ini.

\section{Tan Malaka: Menjadi Guru di Berbagai Penjuru}

Berdasar pada garis keturunannya, Tan Malaka menurut termasuk suku bangsa Minangkabau, yang tinggal di pantai barat Sumatera. Nama kecilnya adalah Ibrahim. Tahun kelahiran Tan Malaka ditemukan bermacam-macam versi, yaitu 1893, 1894, 1895, 2 Juni 1896, 2 Juni 1897, dan 1899. Pada 1897 dinilai sebagai tahun kelahirannya yang paling tepat dengan melihat fakta bahwa pada 1903, ia mengikuti pendidikan di Sekolah Rendah. Berdasar pada fakta tersebut, dapat disimpulkan bahwa pada saat itu ia berusia kurang lebih enam tahun (Poeze, 2000, p. 12).

Keluarga Tan Malaka merupakan penganut Islam yang taat. Ketika ibunya sakit, Tan Malaka sering menyaksikan ibunya membaca surat Yasin dan ayat-ayat suci Al-Quran yang menurutnya dapat mencegah kehadiran malaikat maut, Izrail. Kepada Tan Malaka, ibunya sering bercerita tentang kisah-kisah nabi Adam, Ibrahim, Yusuf, dan Muhammad. Saat mendengar kisah Muhammad, mata Tan Malaka tampak berkacakaca dan sesekali juga berurai air mata tanda keharuan. Ketika beranjak remaja, Tan Malaka telah mahir berbahasa Arab. Ia bahkan sudah dapat menafsirkan ayat-ayat Al-Qur'an. Karena kecerdasannya ini, ia dipercaya menjadi guru muda di surau kampungnya (Fa'al, 2010, p. 17). 
Pada 1903 sampai 1908, Tan Malaka belajar di Sekolah Kelas Dua. Sekolah Kelas Dua lahir karena kebijakan kolonial yaitu politik etis. Menurut van Niel (2009, p. 107), Sekolah Kelas Dua ini pun sama saja tidak berhasil menyediakan kesempatan untuk pendidikan lanjutan, tamatan sekolah ini biasanya mencari jalur pekerjaan baru di Barat. Guru-gurunya sangat menginginkan supaya Tan Malaka melanjutkan pelajarannya, karena ia mempunyai kecerdasan yang tajam sekali. Tan Malaka melanjutkan ke Sekolah Guru Kweekschool Fort de Kock bagi orang Indonesia di Sumatera. Pendidikan Keguruan (Kweekschool) adalah lembaga yang tertua dan sudah ada sejak permulaan abad ke-19. Lembaga ini didirikan oleh kalangan zending dan missie dengan program kursus.

Sekolah Guru Negeri yang pertama, didirikan pada 1851 di Surakarta. Sebelum itu, pemerintah kolonial Belanda telah menyelenggarakan kursus-kursus guru yang diberi nama Normaal Cursus yang dipersiapkan untuk menghasilkan guru-guru Sekolah Desa. Pada abad ke-20, pendidikan guru berubah menjadi tiga macam. Pertama adalah Normaalschool, sekolah guru dengan masa pendidikan empat tahun dan menerima lulusan sekolah dasar dengan masa pendidikan lima tahun, adapun bahasa pengantar yang digunakan adalah bahasa daerah. Kedua, Kweekschool, yaitu sekolah guru empat tahun yang menerima lulusan sekolah dasar berbahasa pengantar Belanda. Ketiga, Hollands Indlandsche Kweekschool, sekolah guru enam tahun dengan bahasa pengantar Bahasa Belanda (Departemen Pendidikan dan Kebudayaan, 1986, p. 119).

Tan Malaka bertemu dengan Horensma di Kweekschool Fort de Kock, Bukittinggi. Horensma adalah guru di For de Kock yang menulis Surat Permohonan pada Van der Lay, Direktur Sekolah Guru Haarlem, Belanda agar mengabulkan menerima Tan Malaka di sekolah tersebut. Di sekolah guru, Tan Malaka merupakan seorang pemuda yang tertib, hormat dan ramah. Tan Malaka memperlihatkan bakat yang luar biasa, khususnya pedagogi. Dalam masa istirahat, ia selalu bergaul dengan anak-anak dan mengajarkan pada mereka baris-berbaris di bawah komando sendiri. Latihan-latihan seperti itu amat disukai para murid. Horensma sangat menginginkan Tan Malaka melanjutkan studinya ke Belanda. Atas bantuan Horensma dan uang patungan masyarakat Suliki, Tan Malaka bersama keluarga Horensma berangkat dengan kapal Wilis ke Belanda (Poeze, 2000, p. 24).

Tan Malaka sekolah di Harleem (kota yang terletak di bagian utara Belanda) dan tinggal bersama seorang pelarian dari Belgia bernama Herman. Darinya, Tan Malaka memiliki akses membaca surat kabar De Telegraaf dan mendorong Tan Malaka memiliki minat politik karena bacaan dari majalah-majalah, brosurbrosur, pamflet-pamflet yang bernada anti-kapitalis dan anti-imperialis. Tan Malaka sangat mengagumi displin keorganisasian dan organisasi Jerman. Serta filsuf yang banyak mempengaruhi anak muda Jerman yaitu Nietzsche. Dengan penuh kesulitan, Tan Malaka membaca Zarathustra satu halaman sampai lima belas kali untuk memahami isinya (Poeze, 2000, p. 45).

Tan Malaka menyesali pelajaran yang diterima di Belanda karena tidak memiliki konektivitas dengan pelajaran yang diterima sebelumnya di Indonesia. Misalnya, sama-sama diajarkan ilmu tumbuh-tumbuhan, tetapi objek kajiannya tidak sama seperti di Indonesia. Begitu juga dengan ilmu bumi, ilmu pedagogi dan lainlain. Tan Malaka mengkritik metode mengajar dalam bentuk hafalan. Kebencian terhadap dunia hafalan sama dengan kebenciannya pada makanan roti dan keju setiap hari. Kebencian terhadap roti keju ini hanya muncul saat menghadapinya saja. Tetapi kebencian terhadap dunia hafalan yang dipaksakan dirasakannya secara terus-menerus, seperti kebenciannya terhadap perbandingan yang tidak adil antara keadaan masyarakat Indonesia dengan Belanda (Malaka, 2008, p. 41).

Pada 1919 Tan Malaka kembali ke Indonesia sebagai guru di perkebunan Sanembah, Deli, Sumatera. Kehidupan yang sangat kontras tampak antara tuan-tuan kolonialis yang mewah dengan kuli-kuli inlander yang sengsara sangat memuakkannya. Pengaruh Revolusi Bolshevik semakin tertanam di dalam dirinya, dan dari situ idenya tentang revolusi sebagai solusi untuk menyelamatkan bangsa Indonesia dari cengkraman kaum kapitalis-kolonialis berkembang cepat dan semakin revolusioner (Abdullah, 1978, p. 145). 
Tan Malaka saat itu juga mulai mengunjungi rumah-rumah para kuli, tidak hanya membicarakan tentang anak didiknya namun juga membicarakan tentang persoalan-persoalan lain yang dihadapi oleh para buruh tersebut. Aktivitasnya dicurigai oleh perusahaan. Dr. Jansseen mengundangnya bersama seluruh administrator untuk dimintai pendapat mengenai sistem pendidikan yang telah dijalankan Tan Malaka. Menurut Tan Malaka kaum buruh harus lebih terampil dan efisien, sehingga mereka bekerja tidak hanya dengan tenaga tetapi juga menggunakan otaknya. Tan Malaka selalu berusaha untuk memperbaiki nasib para kuli tersebut. Namun melihat realitas para kuli kontrak yang tidak juga membaik, Tan Malaka memilih untuk mengundurkan diri sebagai guru. Itu terjadi pada awal 1921 (Ihsanudin, 2010, p. 26).

Pada awal 1921, Tan Malaka memutuskan untuk mengundurkan diri dari Sekolah Perkebunan di Deli (Breman, 2020, 473). Ia kemudian pindah ke Jawa dan bersiap untuk mengabdikan dirinya dengan langkah politik. Setibanya di Jawa, kedatangannya bertepatan dengan penyelenggaraan kongres Serikat Islam (SI) dan temannya bernama Sutopo mengajaknya untuk hadir dan memperkenalkan diri dengan para pemimpin Indonesia yang hadir di sana. SI merupakan suatu organisasi kolosal simbol solidaritas bumiputra, Tan Malaka seketika itu juga terkesan dengan Semaun yang senang karena didatangi oleh seorang terpelajar dan pengagum Marx. Semaun, Ketua Partai Komunis Indonesia (PKI), menyarankan Tan Malaka untuk bergabung dengan dirinya di Semarang dan di sana membantu mendirikan sekolah yang disponsori oleh SI Semarang. Tan Malaka menerima tawaran itu, sehingga gerakan komunis Indonesia mendapatkan salah seorang revolusioner besar paling berbakat (McVey, 2010, p. 205).

Ruang rapat SI Semarang diubah menjadi kelas dan menampung murid perdana berjumlah lima puluh. Biaya menghidupi sekolah ini didasarkan pada derma atau bantuan dari anggotaanggota SI. Dalam waktu beberapa bulan sekolah SI dibuka di berbagai daerah seperti Salatiga, Bandung, dan lainnya. Murid-murid sekolah SI biasanya berasal dari anak-anak anggota SI yang tidak diterima di sekolah pemerintah kolonial. Inilah sebab utama di balik kesuksesan sekolah SI. Sebab lainnya, terletak pada bakat Tan Malaka sendiri di bidang pendidikan. Tan Malaka yang mendapat pendidikan yang sangat baik di sekolahsekolah guru Hindia dan Belanda, sebetulnya dapat memperoleh pekerjaan yang lebih baik daripada mengajar di sekolah SI. Tetapi jiwanya telah tercurahkan pada sekolah SI. Dalam masa permulaan dia menjadi satu-satunya guru di sekolah itu. Guru-guru lulusan sekolah guru Hindia tidak mau bekerja di sekolah Tan Malaka karena digaji rendah sekali. Untuk mendapatkan guru bagi sekolahnya, Tan Malaka mulai mendirikan sekolah guru sendiri. Hal ini menjadi suatu bukti tentang kompetensi yang dapat diandalkan (Poeze, 2000, p. 190).

Untuk meningkatkan sarana dan prasarana, sekolah SI bertumpu pada pasar derma. Atas usul Semaun disepakati untuk mengirimkan muridmurid yang terdiri atas lima anak dari desa. Anakanak tersebut diberi selendang merah yang bertuliskan Rasa Merdika. Mereka ditugaskan untuk menarik simpati rakyat agar dapat membantu memberi uang dengan cara menyanyikan lagu Internasionale. Dalam waktu singkat gerakan tersebut meluas pesat. Muncul anggapan bahwa menyanyikan lagu Internasionale yang dipimpin Tan Malaka merupakan bentuk penghasutan dan perlawanan terhadap pemerintah. Oleh karena itu, setelah memberikan peringatan keras terhadap pemimpin pawai tersebut, pemerintah kolonial melemparkan tuduhan kepada Tan Malaka sebagai dalang dari kegiatan-kegiatan yang dilakukan oleh muridmurid SI. Pihak pemerintah melalui Prokurir Jenderal juga melakukan penyelidikan mengenai sekolah tersebut, di antaranya tentang bahan pelajaran, personalia, dan keuangan, dengan sasaran mencari bahan pertimbangan apakah sekolah tersebut dibiarkan bertahan atau dibubarkan (Ihsanudin, 2010, p. 34).

Kemunduran sekolah SI, seperti penjelasan yang diberikan oleh Shiraishi (1997, p. 320) saat dimulainya zaman reactie, yang diiringi dengan kian tajamnya perpecahan dalam pergerakan, yang ditandai dengan pecahnya SI, telah melahirkan rasa krisis di kalangan pemimpin pergerakan dan aktivis, intelektual bumiputra, buruh dan lainnya. Di satu pihak pemerintahan Fock telah membuat jalan evolusioner menuju otonomi kian suram. Langkah ekonomi Fock bahkan membuat buruh, terutama pegawai negara resah. Di lain pihak, 
perpecahan SI yang meruncing, justru memperbesar harapan persatuan nasional. Dalam gelombang inilah untuk pertama kalinya pada 1921 kata Indonesia muncul dalam khazanah pergerakan untuk menandai Hindia dan solidaritas bumiputra. Intelektual mulai bicara tentang negara Indonesia di Volksraad. Bahasa Melayu, yang telah menjadi bahasa dominan dalam pergerakan, mulai dipakai juga oleh anggota-anggota bumiputranya.

Salah satu anggota terkemuka SI Semarang memberi nasihat kepada Tan Malaka untuk mencurahkan segala energinya pada dunia pendidikan. Setelah tiga atau empat tahun, sudah ada cukup banyak pengikut dalam pergerakan membuat ia dapat bergerak secara aktif di bidang politik. Bahkan, sebelum berangkat ke Rusia, Semaun memberi nasihat serupa kepada Tan Malaka, tetapi nasihat yang itu tidak dapat diikuti oleh Tan Malaka. Tidak ada kader yang cukup banyak dalam partainya, sehingga memaksanya terjun dalam bidang politik (Poeze, 2000, p. 192).

\section{Pemikiran Pendidikan Tan Malaka}

Deli adalah tempat pertama Tan Malaka mengaktualisasikan dirinya sebagai pendidik setelah menempuh pendidikan guru di Belanda. Tugasnya mengajari anak-anak kuli Jawa yang bekerja di perkebunan (Breman, 2020, p. 467). Tan Malaka tidak sendiri, dia ditemani oleh De Way, seorang sosialis dari Belanda. Mereka berdua terlibat dalam perselisihan pandangan tentang visi dan cara pelaksanaan sistem pendidikan.

De Way mendirikan sekolah di semua perkebunan dan melakukan pengawasan ke sekolah-sekolah. Ia mengunjungi sekolah-sekolah tersebut secara rutin dan menulis laporan tentang hal itu. Tan Malaka tidak melihat adanya manfaat dari kunjungan yang dilakukan De Way, dan lebih menyukai mendirikan suatu sekolah teladan (percontohan) di satu tempat yang sentral (terpusat). Di sini, ia mempelajari akhlak, kemauan, dan perhatian para murid masingmasing. Untuk itu, ia harus secara kontinyu berhubungan dengan para orang tua murid. Hanya dengan menjalin hubungan dengan para kuli kontrak, ia memperoleh kepercayaan dari mereka. Tetapi bersamaan dengan itu, para tuan (kebanyakan adalah orang Eropa) menaruh kecurigaan terhadapnya. Hubungan dengan para kuli semakin intensif, tidak jarang mereka berkunjung ke rumah Tan Malaka dan turut membicarakan persoalan yang dihadapi oleh anakanaknya ketika di sekolah (Poeze, 2000, p. 118).

Tan Malaka diundang dalam pertemuan guna menyelesaikan perselisihan tersebut sambil memberikan pandangan singkat mengenai sistem pendidikan. Baginya, tujuan utama penyelenggaraan pendidikan anak-anak kuli adalah untuk mempertajam kecerdasan dan memperkokoh kemauan serta memperhalus perasaaan si murid. Selain mengasah kognitif dan empati, ia menegaskan perlunya menanamkan kebiasaan bekerja tangan. Ia juga secara konsisten memberi pemahaman kepada para murid bahwa pekerjaan fisik sama mulianya dengan pekerjaan yang lebih banyak mengandalkan otak atau kognitif. Sanembah Mij dan Deli tidak akan rugi jika banyak buruh halus dan kasar memiliki kecakapan kerja yang baik serta mempunyai keinginan hidup yang tinggi (Malaka, 2008, p. 84).

Pengalaman mengajar di Deli menjadi percik-percik pemikiran Tan Malaka yang penting di dunia pendidikan, bahkan setelah ia hijrah ke Semarang pada Juni 1921. Visi pendidikan Tan Malaka yang tidak bebas nilai. Sistem pendidikan itu tidak berpihak kepada kaum tertindas yaitu kuli kontrak dan buruh, membuatnya semakin yakin bahwa pendidikan adalah sesuatu yang sangat penting dalam membebaskan kaum tertindas. Saat mengajar di Semarang, Tan Malaka menulis konsep pendidikan dalam bentuk brosur berjudul SI Semarang dan Onderwijs. Surat kabar Soeara Ra'jat bahkan memuat tulisan tersebut sebanyak dua kali pada Desember 1921. Tulisan tersebut menitikberatkan tentang sistem pendidikan yang harusnya disesuaikan dengan keperluan dan citacita masyarakat miskin. Tulisan tersebut ditujukan kepada anggota-anggota SI di Semarang yang sudah banyak mendengar sekolah itu, dan juga kepada orang-orang di seluruh Hindia. Sistem itu tentu masih belum sempurna karena masih tergolong baru berjalan beberapa waktu. Tetapi dari reaksi-reaksi negatif yang dinyatakan pers dan pemerintah kolonial dapat ditarik kesimpulan bahwa cara pendidikan itu memang bermanfaat bagi rakyat Indonesia (Poeze, 2000, p. 180). 
Tujuan Tan Malaka bukan mendidik murid menjadi juru tulis seperti sekolah pemerintah kolonial, tetapi untuk mencari nafkah diri sendiri dan keluarga, juga untuk membantu rakyat dalam pergerakannya. Jelas bahwa dasar yang dipakai ialah kerakyatan, hidup bersama rakyat untuk mengangkat derajat rakyat jelata. Bukanlah untuk menjadi satu kelas yang terpisah dari rakyat dan dipakai oleh pemerintah penindas bangsa sendiri. Sesuai dengan dasar dan tujuan itu, metode pendidikan yang diterapkan telah disesuaikan dengan kepentingan rakyat jelata, pekerjaan rakyat sehari-hari, cita-cita ideal rakyat, dan pergerakan serta organisasi rakyat (Malaka, 2008, p. 94).

Tan Malaka (2011, p. 22) meringkas tiga hal penting yang menjadi maksud dan tujuan pendidikan sekolah SI. Pertama, pendidikan dapat menjadi modal untuk mengarungi hidup dan mendapatkan kebebesan, terutama melalui kemampuan berhitung, menulis, ilmu bumi, bahasa Belanda, Jawa, Melayum dan sebagainya. Kedua, memberikan murid-murid hak untuk menjalankan hobinya, yakni kesukaan hidup dengan jalan pergaulan (vereniging). Ketiga, menunjukkan kewajiban untuk mengabdi terhadap berjuta-juta kromo atau rakyat kecil.

Adapun penjelasan dari maksud dan tujuan pendidikan sekolah SI yang pertama berarti seluruh pengajaran sekolah harus berorientasi pada membangun kemerdekaan. Hal ini dapat ditempuh dengan jalan pada kebudayaan tradisional, menyanyikan lagu-lagu Jawa, dan menggambar berbagai jenis wayang. Meskipun pengajaran tidak menggunakan Bahasa Belanda sebagai pengantar, tetapi penting untuk menguasai Bahasa Belanda sebagai alat perlawanan terhadap para pemilik modal. Metode pengajaran berpusat pada murid yang didorong untuk mencari dan menggunakan metodenya sendiri serta memilih pelajaran sesuai dengan kemampuannya. Tan Malaka memberikan kritik terhadap gaya pendidikan yang guru-gurunya "mabuk" metode mengajar, sehingga anak-anak tidak bisa mencari jalan sendiri (Malaka, 2011, p. 23).

Selanjutnya, maksud dan tujuan yang kedua adalah pendidikan harus menjadi ruang bermain anak-anak. Pada saat bermain, dapat secara leluasa berinteraksi satu sama-lain. Hal ini berguna bagi kehidupan mereka kelak agar menjadi manusia yang memiliki orientasi hidup bersama dan tidak semata-mata mencari kesenangan sendiri. Guru tidak boleh menjadi diktator dalam proses pengajaran. Mereka hanya boleh terlibat jika diminta atau terdapat kesalahan yang dilakukan anak-anak ketika belajar. Pendidikan juga harus mampu mendorong murid-murid untuk membuat perkumpulan. Bagi Tan Malaka, perkumpulan yang didirikan bukan hendak mendidik anak-anak menjadi Gromopon-hanya pintar menghafal, tetapi tidak kritis dan inovatif-tetapi supaya murid-murid dapat berpikir dan berjalan sendiri. Tan Malaka juga mengharapkan realisasi pendirian perkumpulan toneel (sandiwara), wayang, bernyanyi, dan menerbitkan surat kabar (Malaka, 2011, p. 27).

Penjelasan ketiga, pendidikan tidak boleh menghasilkan kaum yang terpisah dari rakyat. Tan Malaka memberikan kritik terhadap sekolah pemerintah kolonial yang tidak memiliki kewajiban untuk menaikkan derajat rakyat. Sekolah governement mengajarkan kebersihan kepada murid-murid. Jika murid-murid sekolah itu sudah dewasa, para murid sekolah governement yang berasal dari golongan bangsawan tidak akan membangunkan kebiasaan kebersihan pada kaum melarat. Sekolah itu berupaya memberikan jarak, murid-murid dididik untuk merasa benci terhadap pekerjaan tangan yang dihubungkan dengan rakyat yang kotor dan bodoh.

Di sekolah SI, kebersihan diajarkan tidak dengan cara didikte, tetapi belajar sendiri untuk memahami kebersihan. Murid-murid SI diajarkan untuk tidak memandang rendah pekerjaan fisik. Selanjutnya, setelah berhasil membuang sifat yang dapat mendatangkan benci terhadap kaum kromo yang bekerja megandalkan fisik, maka murid-murid juga diarahkan untuk berhubungan dengan kaum melarat. Pelajaran yang didapat oleh murid didorong untuk mendiskusikan nasib rakyat, agar mereka terbangun hatinya dan berani bicara dalam vergadering SI atau buruh. Murid dididik untuk lantang berpidato, dan rapat-rapat SI menjadi salah satu media untuk mendidik raga dan hati mereka. Mereka juga dididik untuk mampu memikirkan dan menjalankan peraturan pergaulan hidup, mendidik untuk fasih dan berani bicara. Materi pendidikan ini sangat berharga daripada sekedar mengetahui berapa banyaknya sungai-sungai di Kalimantan umpamanya (Malaka, 2011, p. 30). 
Tan Malaka (2011, p. 31) membuatnya menjadi empat catatan penting. Pertama, sekolah SI mendirikan dan mengurus sendiri vereniging yang dapat berguna secara lahir dan batin (kemampuan fisik dan intelektual). Berkaitan dengan vereniging, anak-anak itu sudah belajar menciptakan kerukunan dan merasakan indahnya pergaulan hidup. Kedua, di sekolah SI diceritakan nasib dan sebab-sebab kaum melarat di Hindia Belanda dan di daerah lain. Ketiga, dalam vergaderingSI dan buruh, murid-murid yang sudah bisa mengerti lalu diajak untuk mendengarkan suara kaum kromo dan diminta untuk berpidato sesuai dengan pandangannya sendiri berdasar pada kondisi objektif yang dialami oleh kaum kormo. Keempat, jika kelak mereka tumbuh dewasa, hubungan antara pelajaran yang sudah didapat di sekolah SI dengan ikhtiar untuk membela rakyat tidak berakhir dalam buku kenang-kenangan, tetapi sudah menjadi watak dan kebiasaan masingmasing.

Sebelum kedatangan orang Belanda, Tan Malaka berpandangan bahwa masyarakat Indonesia telah memiliki pendidikannya sendiri. Bahkan, anak-anak Jawa telah memiliki pengetahuan empirik mengenai musim tanam padi. Secara langsung mereka turut membantu orangtua dengan membajak dan menuai padi. Musim tanam padi bagi penduduk mempunyai arti khusus. Sambil membangun rumah, anak-anak tertarik pada cerita yang didongengkan oleh orang tuanya. Wayang dan gamelan adalah bagian dari pendidikan budaya. Industri batik dan pelayaran memberi sumbangannya tersendiri. Orang Jawa pada 1600 sudah berlayar sampai di Persia dan Peking. Jepara dan Gresik mempunyai galangan kapal dan industri yang kuat. Semua ini telah dihancurkan oleh Belanda, kehancuran industri turut menghancurkan pendidikan. Bagi Tan Malaka pendidikan tidak berdiri sendiri, tidak bergantung di udara, ia bergantung pada keadaan sosial. Menurutnya, Orang Jawa dan Sumatera dalam hal apapun tidak boleh terbelakang, apalagi dibandingkan dengan bangsa timur manapun (Poeze, 2000, p. 187).

Penetrasi kapitalisme asing telah membuat keadaan Indonesia berubah. Roda kapitalisme seperti pabrik, perkebunan, dan lembaga pemerintah memerlukan pegawai rendahan
(Poeze, 2012). Pendidikan diselenggarakan untuk mendidik orang-orang Indonesia agar dapat berkontribusi terhadap keuntungan kapitalisme asing. Tetapi pendidikan itu dapat menciptakan kesadaran untuk melakukan perlawanan.

Program pendidikan Tan Malaka sejak awal menitikberatkan pada gagasan anti-kolonial dan juga anti-kapitalisme. Di sekolah yang ia dirikan, ia mendorong kemajuan seni tradisional, seperti wayang, nyanyian, sandiwara dan mencoba mengembangkan kejuruan, dengan itu pekerjaan tangan, seperti pada zaman makmur dulu. Bagian programnya yang anti-kolonial dan nasional murni ditambah dengan pelajaran dalam pengertian sosialis. Para murid dibentuk menjadi pemimpin rakyat, khususnya dalam perkumpulanperkumpulan, baik di dalam maupun di luar sekolah. Mereka diminta untuk mempraktikkan gerakan massa. Salah satu yang cukup menonjol dari SI adalah kebebasan dalam belajar. Para murid diizinkan untuk belajar sebebas-bebasnya, baik di dalam maupun di luar sekolah. Hal ini bertujuan agar dapat membentuk pendirian mereka sendiri dan dapat dengan mudah mengadakan organisasiorganisasi yang di dalamnya guru hanya mempunyai tugas sebagai pembimbing. Unsurunsur yang digabungkan Tan Malaka di sekolah SI terinspirasi pada kebebasan anak-anak di sekolah sewaktu ia berada di Belanda. Sikapnya yang antikolonial mendorongnya untuk menjangkau kembali masa lampau yang diidamkan (Poeze, 2000, p. 191).

\section{Simpulan}

Penelitian ini mencoba memberikan pandangan bahwa pemikiran-pemikiran pendidikan Tan Malaka tidak berjarak antara teori dan praktik. Tan Malaka bukan hanya sebagai seorang pemikir pendidikan tetapi juga seorang praktisi. Sikap politiknya yang anti-kolonial dibentuk dari hasil bacaannya berdasar pada referensi bacaan bercorak sosialis yang dibenturkan dengan kenyataan hidup antara kaum penjajah dan rakyat jajahan. Oleh karena itu, perspektif pendidikan Tan Malaka adalah berwatak anti-kolonial.

Modal awal Tan Malaka sebagai seorang pemikir dan praktisi pendidikan dapat dilihat dari dual hal. Pertama, pengalamannya yang 
berbenturan dengan keadaan sosiologis masyarakat Indonesia. Kedua, kompetensi akademiknya pada ilmu pedagogi. Dua hal yang sudah tentu menjadi instrumen itu melahirkan pemikiran pendidikan revolusioner.

Pilihan untuk melanjutkan sekolah guru di Belanda memberikan inspirasi bagi Tan Malaka dalam menemukan nilai-nilai kebebasan. Di Belanda, Tan Malaka merekam betul semangat intelektual masyarakat Eropa dan ia juga melihat gambaran kehidupan mewah dari penindasan yang dilakukan di tanah airnya. Hal ini yang mendorongnya untuk kembali ke Indonesia dan menjadikan pendidikan sebagai alat politik membangun kesadaran merdeka.

Esensi dari pemikiran pendidikan Tan Malaka adalah melahirkan manusia merdeka dan memerdekakan masyarakat Indonesia. Kurikulumnya dibuat agar dapat memiliki orientasi yang selaras dengan kerja-kerja politik kaum pergerakan. Sekolah SI adalah sekolah politik di mana peserta dididiknya sedari muda dididik agar menjadi manusia bebas. Kemudian anak-anak muda ini didorong memiliki rasa empati terhadap akibat dari penjajahan. Setelah semuanya siap, murid-murid Tan Malaka sudah terampil dalam membuat perkumpulan-perkumpulan, ahli berpidato dan mampu mengorganisir dan mengorganisasi massa di kemudian hari untuk kemerdekaan Indonesia.

\section{Referensi}

Abdullah, T. (Ed). (1978). Manusia dalam kemelut sejarah. Jakarta: LP3ES.

Breman, J. (2020). Colonialism and Its Racial Imprint. Sojourn: Journal of Social Issues in Southeast Asia, 35(3), 463-492. doi: $10.2307 / 26937814$

Departemen Pendidikan dan Kebudayaan. (1986). Pendidikan Indonesia dari jaman ke Jaman. Jakarta: Balai Pustaka.

Fa'al, F. M. (2010). Negara dan revolusi Sosial: pokok-pokok pikiran Tan Malaka. Yogyakarta: Resist Book.

Harry A. Poeze. (2012). From Foe to Partner to Foe Again: The Strange Alliance of the Dutch Authorities and Digoel Exiles in Australia, 1943-1945. Indonesia, (94), 5784. doi:10.5728/indonesia.94.0057
Ihsanudin. (2010). Tan Malaka dan revolusi proletar. Yogyakarta: Resist Book.

Malaka, T. (1987). Naar de 'Republiek Indonesia' Menuju Republik Indonesia. Jakarta: Yayasan Massa.

Malaka, T. (2000). Aksi Massa. Jakarta: Teplok Press.

Malaka, T. (2000). Madilog. Jakarta: Teplok Press.

Malaka, T. (2008). Dari Penjara ke Penjara. Yogyakarta: Narasi.

Malaka, T.(2011). Serikat Islam Semarang dan onderwijs. Jakarta: Pustaka Kaji.

McVey, R. (2010). Kemunculan komunisme Indonesia. Depok: Komunitas Bambu.

Poeze, H. A. (2000). Pergulatan menuju republik 1897-1925. Jakarta: Grafiti.

Rambe, S. (2003). Pemikiran politik Tan Malaka. Yogyakarta: Pustaka Pelajar.

Shiraishi, T. (1997). Zaman bergerak: Radikalisme rakyat di Jawa 1912-1926. Jakarta: Grafiti.

Suwignyo, A. (2013). The Great Depression and the changing trajectory of public education policy in Indonesia, 1930-42. Journal of Southeast Asian Studies, 44(3), 465-489. http://www.jstor.org/stable/43863216

Tim Tempo (2010). Tan Malaka: Bapak Republik yang dilupakan. Jakarta: Kepustakaan Populer Gramedia.

van Niel, R. (2009). Munculnya elite modern Indonesia. Jakarta: Pustaka Jaya. 